\title{
Word lists for testing cognitive biases toward body shape among men and women
}

\author{
Amy E. Wojtowicz and Kristin M. von Ranson \\ University of Calgary, Calgary, Alberta, Canada
}

\begin{abstract}
The present study developed word lists describing three categories of body build - fat, thin, and muscular - for use in investigating cognitive risk factors for body dissatisfaction. Fifty-one men and 51 women rated the categorization, valence, and familiarity of 284 body-related adjectives in order to develop the final lists. The normative frequency of each of the 284 words was determined using an index of American English. The final 19- to 26-item word lists were constructed so that the average number of syllables, word length, word frequency, and mean percentage of categorization agreement were comparable. The availability of these word lists will facilitate future cognitive research into a key risk factor for eating disorders.
\end{abstract}

Epidemiological studies consistently indicate that women are at a substantially greater risk for developing clinical and subclinical eating disorders than are men (Fairburn $\&$ Beglin, 1990). In fact, males account for only $5 \%-10 \%$ of documented anorexia nervosa cases and $10 \%-15 \%$ of bulimia nervosa cases (American Psychiatric Association, 2000). The pronounced discrepancy in the prevalence of anorexia nervosa and bulimia nervosa between males and females has prompted researchers to study gender differences in body image and has led to questions about different pathways that may contribute to the development of eating disorders in men and women.

Relatively little is known about risk factors related to body dissatisfaction in males (Drewnowski, Kurth, \& Krahn, 1995). Although it is relatively uncommon for men to perceive their bodies as being too large (McCreary \& Sadava, 2001), the prevalence of body image dissatisfaction in males may have been underestimated by traditional methods. A major limitation of most previous studies examining gender and body image is that they have focused solely on dimensions of fatness and thinness, ignoring the dimension of muscularity (Cohane \& Pope, 2001). Instead of desiring a thin figure, men typically desire a muscular and heavy body shape (McCreary \& Sadava, 2001). Studies that differentiate between fat and muscularity are needed to more precisely examine the extent to which males display body dissatisfaction (Cohane \& Pope, 2001).

A second potential limitation of previous research investigating gender differences in body image is that most studies have relied exclusively on self-report instruments. It may be socially unacceptable for males to admit that they are experiencing body image dissatisfaction and thus, to evade stigmatization, they may be less forthcoming than females about their symptoms (Cohane \& Pope, 2001).
Recently, researchers have started to apply the methods of cognitive science to the study of body image. By using dependent variables that are difficult to falsify, cognitive tasks provide more information than methodologies that utilize only self-report measures. Cognitive tasks tend to reduce problems of demand characteristics and response bias because deliberate denial of body image issues is unlikely to affect one's response to a cognitive task (Vitousek \& Orimoto, 1993).

The essence of the cognitive perspective is that an individual's attitude toward his or her physical attributes biases the manner in which that individual processes stimuli related to body shape. In other words, people who are dissatisfied with their bodies may attend to, encode, store, and retrieve body shape stimuli differently than they do neutral stimuli. For example, individuals may process information pertaining to negative body image more extensively than they process information associated with positive body image, which in turn would reinforce their negative beliefs about their own body. Such information processing biases may serve to maintain negative body shape and weight attitudes and may explain the persistence of body dissatisfaction in some individuals (Vitousek \& Orimoto, 1993).

Few studies have examined gender differences in attentional bias toward words relating to body appearance, weight, and shape. Studies that have examined gender differences (e.g., Ben-Tovim, Walker, \& Douros, 1993; Green \& McKenna, 1993) have failed to consider that key elements of body shape ideals differ between men and women; these studies presented word lists that focused exclusively on the dimensions of fatness and thinness and ignored the dimension of muscularity. To expand our knowledge of gender-specific cognitive risk factors for body dissatisfaction in men, stimuli that describe the

K. M. von Ranson, kvonrans@ucalgary.ca 
dimension of muscularity are needed. The present study aimed to develop a list of words describing a muscular physique and, for comparison, word lists describing thin and fat physiques.

\section{METHOD}

\section{Participants}

A total of 102 students at the University of Calgary, 51 male and 51 female, received course credit in exchange for their participation in the study. To maximize accurate comprehension and interpretation of the words, participants were required to have English as their first language to be eligible to participate.

\section{Measures}

Sociodemographic information was collected by having participants complete a questionnaire requesting gender, age, ethnicity, height, weight, marital status, and number of years in university.

\section{Procedure}

Prior to data collection, the study was approved by the institutional research ethics board. Data were collected from groups of 5 to 10 participants. All participants gave their informed consent, after which each was presented with a list of 284 words in random order, 207 of which were body shape adjectives ( 77 body-related adjectives not describing fatness, thinness, or muscularity, e.g., "tanned," were also included in data collection but are not discussed further in this article). Body shape adjectives that described overweight, thin, and muscular physiques were generated through consultation with colleagues and utilization of multiple thesauruses. Participants were asked to provide ratings of the meaning of the word, the valence of each word, and their familiarity with each word. Specifically, participants were asked to categorize each word into one of three groups: (1) adjectives describing an overweight physique, (2) adjectives describing a thin physique, and (3) adjectives describing a muscular physique. Additionally, participants were instructed to categorize words as "other" if they felt that the word did not fall into any of the three categories and as "unsure" if they did not comprehend the meaning of the word. If participants felt that the word fit into more than one category (e.g., both the muscular and overweight categories), they were told to check all the categories to which they felt that the word belonged. Next, participants were asked to subjectively rate the valence of each word on a scale from -3 (very negative) to +3 (very positive). Finally, participants were asked to subjectively rate their familiarity with each word on a scale from 0 (never seen or heard the word) to 9 (as common as "the" or " $a$ ").

Given the significant length of the word-rating task, two versions were developed to minimize the potential impact of fatigue on participants' responses. Half of the participants were presented with the first version, and the other half were presented with a second version, in which words were presented in the opposite order of the first version. After completing the word categorization task, participants were debriefed and provided with the opportunity to ask questions.

The normative frequency of each word was derived from an index of American English published by Kučera and Francis (1967). This index quantifies the average number of times a word is presented in print per one million words. The word frequency ratings were used in addition to the results of the word categorization task to ensure that all finalized word lists were comparable.

\section{Statistical Analysis}

Men's and women's responses on the word rating task were combined to develop the finalized word lists, thus making the stimuli set usable for testing cognitive biases in both men and women. For a word associated with fatness, thinness, or muscularity to be considered for inclusion on the finalized word lists, at least $90 \%$ of participants were required to have comprehended its meaning and at least $80 \%$ of participants had to have agreed on the categoriza- tion of the word. In addition, no more than $20 \%$ of the participants could have categorized the word in one or more of the two remaining categories. These criteria were established in order to maximize the length of the word lists without substantially diminishing agreement on the meaning of words.

Using the words that met the above criteria, word lists were developed in which the average number of syllables, word length, word frequency, and word familiarity were matched as closely as possible. Multiple one-way ANOVAs were performed to compare the valence of the different word groups and to ensure that the word lists were matched on all of the aforementioned characteristics. In addition, a Kruskal-Wallis test was performed to determine whether the percentage of categorization agreement was comparable across the three word types (fat, thin, and muscular).

\section{RESULTS}

\section{Participant Characteristics}

Independent-samples $t$ tests and Pearson chi-square tests were used to examine gender differences on demographic characteristics. There were no significant differences between men and women in age, ethnicity, or level of education. Overall, participants had a mean age of 22.4 years $( \pm 5.3)$ and had 3.4 years $( \pm 1.1)$ of postsecondary education. The majority (75.5\%) identified their ethnicity as Caucasian; $13.7 \%$ identified as Asian, $5.9 \%$ as East Indian, and $5 \%$ as mixed. Most participants had never been married (84.3\%). The mean Body Mass Index (BMI) of participants was $23.6( \pm 5.3) \mathrm{kg} / \mathrm{m}^{2}$.

\section{Word Lists}

Twenty-six words describing a fat physique, 22 words describing a thin physique, and 19 words describing a muscular physique were selected for inclusion in the word lists (see the Appendix). Means and standard deviations of the number of letters, number of syllables, word frequency, word familiarity, word valence, and percentage of categorization agreement for each word list are presented in Table 1. As noted in the table, word lists were comparable on all characteristics with the exception of valence. Follow-up Bonferroni tests indicated that words associated with fatness were rated significantly more negatively than words associated with thinness and muscularity. Words associated with muscularity were rated significantly more positively than words associated with thinness.

Subsequent analyses were conducted examining possible gender differences in the word-rating task using the average ratings of all of the words included in the finalized word list for each gender. A series of independent-groups $t$ tests was performed, comparing valence and familiarity ratings between men and women separately for each word type. In addition, Mann-Whitney tests were performed comparing percentage of categorization agreement between men and women separately for each word type. All comparisons were nonsignificant.

\section{DISCUSSION}

The purpose of the present study was to develop an improved set of stimuli for use in cognitive paradigms 
Table 1

Characteristics of Lists of Words Associated With Fatness, Thinness, and Muscularity

\begin{tabular}{|c|c|c|c|c|c|c|c|}
\hline \multirow[b]{2}{*}{ Stimulus Characteristics } & \multicolumn{2}{|c|}{$\begin{array}{l}\text { Fat Stimuli } \\
\text { (26 words) }\end{array}$} & \multicolumn{2}{|c|}{$\begin{array}{c}\text { Thin Stimuli } \\
\text { (22 words) }\end{array}$} & \multicolumn{2}{|c|}{$\begin{array}{l}\text { Muscular } \\
\text { Stimuli } \\
\text { (19 words) }\end{array}$} & \multirow[b]{2}{*}{$F$} \\
\hline & $M$ & $S D$ & $M$ & $S D$ & $M$ & $S D$ & \\
\hline Percentage & 93.6 & 6.2 & 90.8 & 4.9 & 91.1 & 5.2 & $\chi^{2}=5.2$ \\
\hline Number of letters & 6.1 & 1.8 & 6.5 & 1.9 & 6.0 & 1.7 & 1.3 \\
\hline Number of syllables & 2.0 & 0.6 & 2.1 & 0.7 & 1.6 & 0.8 & 2.6 \\
\hline Frequency & 18.0 & 35.6 & 12.0 & 22.4 & 42.9 & 61.9 & 1.2 \\
\hline Familiarity & 6.0 & 0.9 & 6.0 & 0.9 & 6.7 & 0.7 & 1.4 \\
\hline Valence & -1.7 & 0.4 & -0.7 & 0.9 & 1.6 & 0.4 & $4.3^{*}$ \\
\hline
\end{tabular}

Note-Percentage $=$ the percentage of the sample that agreed with the categorization of the word. Frequency $=$ number of times word is presented in print per million words (Kučera \& Francis, 1967). Familiarity ratings were made on a 9-point scale $(0=$ never seen or heard word before, 9 = as common as "the" or " $a$ "). Valence ratings were made on a 7-point scale $(-3=$ very negative, $+3=$ very positive $)$. The first row of the final column gives the results of a Kruskal-Wallis test $\left(\chi^{2}\right)$ performed to examine the percentage of categorization agreement across the three word types. The remaining rows of this column give the results of multiple one-way ANOVAs ( $F$ tests) performed to examine the number of letters, number of syllables, frequency, familiarity, and valence across the three word types. ${ }^{*} p<.05$.

to study body image in men and women. Previous cognitive research oriented toward female body image has largely ignored the dimension of muscularity. In addition to thinness- and fatness-related words, the present stimuli lists include muscularity-related words, which will help increase knowledge related to body image disturbance, particularly among men, who tend to strive for a heavier, not lighter, physique (McCreary \& Sadava, 2001). Studies that differentiate between fatness and muscularity are clearly needed in order to more carefully examine the extent to which males display body image pathology (Cohane \& Pope, 2001). The use of these standardized word lists in cognitive methodologies will allow a more thorough analysis and comparison of a wider range of body image dimensions in men and women than previous word lists have allowed.

The word lists were statistically matched on number of letters, number of syllables, word frequency, word familiarity, and percentage of categorization agreement. When using these matched word lists, investigators can more precisely examine whether individuals display an attentional or memory bias toward particular types of words and can therefore more confidently rule out noise such as variability in familiarity or length of individual words, thus increasing studies' internal validity.

More fatness- and thinness-related words met the criteria for inclusion in the final stimuli set than did muscularityrelated words. This finding reflects the fact that in English, many more words describe fatness and thinness than muscularity. As a result, fatness- and thinness-related words had a higher probability of meeting the criteria for the final lists than the other body shape categories.

The finding that fatness-related words were rated significantly more negatively than all other word types is consistent with previous studies that presented fatnessand thinness-related words to undergraduate females and found that the former were rated more negatively than the latter (Cassin \& von Ranson, 2005; Rieger et al., 1998). Such results are not surprising given the stigma associated with obesity that occurs in North American society (Falkner et al., 1999; Rothblum, Brand, Miller, \& Oetjen, 1990). The novel finding that muscularity-related words tended to be positively viewed by both men and women is consistent with growing cultural trends emphasizing the importance of fitness on long-term health as well as on attractiveness for both genders.

A strength of the newly developed word lists is that they consist only of adjectives related to body shape. Previous studies examining cognitive biases toward body shape stimuli combined words pertaining to weight, eating, food, and body parts into single lists (Cooper \& Fairburn, 1992, 1993), making it impossible to draw conclusions about subcategories of words. Homogeneous word lists make it easier for researchers to draw firmer conclusions about the types of words associated with cognitive biases.

Despite the strengths of these word lists, there are limitations to acknowledge. First, since the word lists were developed using a university population, researchers should use caution in generalizing them to clinical or community populations or to different age groups, in the absence of further study. Second, language is strongly influenced by culture, so modification of the word lists may be required for individuals outside North America. Third, it is important to note that the stimuli must be used in their entirety or their comparability will be compromised.

In conclusion, we hope that the word lists developed in the present study will be useful to researchers utilizing cognitive paradigms to study body image. In the past, investigators have used a variety of stimuli in research regarding body dissatisfaction, making it nearly impossible to compare the results of different studies (Dobson \& Dozois, 2004). If the present word lists serve as a standard in future research, they may help clarify discrepant findings across various studies. 


\section{AUTHOR NOTE}

A.E.W. presented portions of this research at the 2004 Association for Advancement of Behavior Therapy Conference in New Orleans. This article is based on the MSc thesis research of A.E.W. (formerly Amy E. Baxter), which was completed under the supervision of K.M.v.R. and which was supported by a Canada Graduate Scholarship from the NSERC of Canada to A.E.W. We thank Carly McMorris and Paige Marshall, who assisted with data collection and entry, and Christopher Sears, Tak Fung, and Stephanie Cassin for their assistance with study design and analysis. We also thank the students who participated in this study. Correspondence should be directed to K. M. von Ranson, Department of Psychology, University of Calgary, 2500 University Drive N.W., Calgary, AB, T2N 1N4 Canada (e-mail: kvonrans@ucalgary.ca).

\section{REFERENCES}

American Psychiatric Association (2000). Diagnostic and statistical manual of mental disorders (4th ed., text revision). Washington, DC: Author.

Ben-Tovim, D. I., Walker, M. K., \& Douros, G. (1993). Failure to demonstrate gender differences in interference to information-processing of body-shape stimuli. Perceptual \& Motor Skills, 76, 456-458.

Cassin, S. E., \& von Ranson, K. M. (2005). Word lists for testing cognitive biases in eating disorders. European Eating Disorders Review, 13, 216-220.

Cohane, G. H., \& Pope, H. G., JR. (2001). Body image in boys: A review of the literature. International Journal of Eating Disorders, 29, 373-379.

CoOPER, M. J., \& FaIrburn, C. G. (1992). Selective processing of eating, weight, and shape related words in patients with eating disorders and dieters. British Journal of Clinical Psychology, 31, 363-365.

Cooper, M. J., \& Fairburn, C. G. (1993). Demographic and clinical correlates of selective information processing in patients with bulimia nervosa. International Journal of Eating Disorders, 13, 109-116.
Dobson, K. S., \& Dozors, D. J. A. (2004). Attentional biases in eating disorders: A meta-analytic review of Stroop performance. Clinical Psychology Review, 23, 1001-1022.

Drewnowski, A., Kurth, C. L., \& Krahn, D. D. (1995). Effects of body image on dieting, exercise, and anabolic steroid use in adolescent males. International Journal of Eating Disorders, 17, 381-386.

Fairburn, C. G., \& Beglin, S. J. (1990). Studies of the epidemiology of bulimia nervosa. American Journal of Psychiatry, 147, 401-408.

Falkner, N. H., French, S. A., Jefferry, R. W., NeumarkSztainer, D., Sherwood, N. E., \& Morton, N. (1999). Mistreatment due to weight: Prevalence and sources of perceived mistreatment in women and men. Obesity Research, 7, 572-576.

Green, M. W., \& McKenna, F. P. (1993). Developmental onset of eating related color-naming interference. International Journal of Eating Disorders, 13, 391-397.

KuČera, H., \& Francis, W. N. (1967). Computational analysis of present-day American English. Providence, RI: Brown University Press.

McCreary, D. R., \& SADAVA, S. W. (2001). Gender differences in relationships among perceived attractiveness, life satisfaction, and health in adults as a function of body mass index and perceived weight. Psychology of Men \& Masculinity, 2, 108-116.

Rieger, E., Schotte, D. E., Touyz, S. W., Beumont, P. J. V., GRIFFITHS, R., \& RusselL, J. (1998). Attentional biases in eating disorders: A visual probe detection procedure. International Journal of Eating Disorders, 23, 199-205.

Rothblum, E. D., Brand, P. A., Miller, C. T., \& Oetjen, H. A. (1990). The relationship between obesity, employment discrimination, and employment-related victimization. Journal of Vocational Behavior, 37, 251-266

Vitousek, K. B., \& Orimoto, L. (1993). Cognitive-behavioral models of anorexia nervosa, bulimia nervosa, and obesity. In K. S. Dobson \& P. C. Kendall (Eds.), Psychopathology and cognition (pp. 191-243). San Diego: Academic Press.

APPENDIX

Word Lists for Testing Cognitive Biases

\begin{tabular}{lrrcrcc}
\hline \multicolumn{1}{c}{ Word } & $\begin{array}{c}\text { Percentage } \\
\text { Agreement }\end{array}$ & $\begin{array}{c}\text { Number } \\
\text { of Letters }\end{array}$ & $\begin{array}{c}\text { Number of } \\
\text { Syllables }\end{array}$ & $\begin{array}{c}\text { Mean } \\
\text { Frequency }\end{array}$ & $\begin{array}{c}\text { Mean } \\
\text { Familiarity }\end{array}$ & $\begin{array}{c}\text { Mean } \\
\text { Valence }\end{array}$ \\
\hline Bloated & & \multicolumn{7}{c}{ Fat Stimuli } & & & \\
Blubbery & 83.3 & 7 & 2 & 3 & 6.33 & -1.74 \\
Chubby & 96.1 & 8 & 3 & 0 & 5.37 & -2.40 \\
Chunky & 100.0 & 6 & 2 & 2 & 7.15 & -1.57 \\
Doughy & 99.0 & 6 & 2 & 1 & 6.39 & -1.91 \\
Enormous & 96.1 & 6 & 2 & 0 & 4.66 & -1.79 \\
Fat & 94.1 & 8 & 3 & 37 & 6.47 & -2.10 \\
Flabby & 100.0 & 3 & 1 & 60 & 8.13 & -2.35 \\
Heavy & 99.0 & 6 & 2 & 0 & 6.75 & -1.87 \\
Hefty & 93.1 & 5 & 2 & 110 & 7.17 & -1.43 \\
Lumpy & 83.3 & 5 & 2 & 1 & 5.53 & -1.14 \\
Obese & 92.2 & 5 & 2 & 2 & 5.17 & -1.67 \\
Overfed & 100.0 & 5 & 2 & 0 & 7.37 & -2.53 \\
Overstuffed & 97.0 & 7 & 3 & 0 & 5.29 & -1.86 \\
Padded & 94.1 & 11 & 3 & 0 & 5.19 & -1.91 \\
Paunchy & 86.3 & 6 & 2 & 5 & 5.76 & -1.18 \\
Plump & 86.3 & 7 & 2 & 2 & 4.31 & -1.62 \\
Porky & 99.0 & 5 & 1 & 4 & 6.11 & -1.55 \\
Potbellied & 99.0 & 5 & 2 & 0 & 5.70 & -2.27 \\
Pudgy & 97.1 & 10 & 3 & 0 & 6.25 & -1.91 \\
Puffy & 100.0 & 5 & 2 & 0 & 6.25 & -1.84 \\
Round & 88.2 & 5 & 2 & 2 & 5.18 & -1.60 \\
Stuffed & 97.0 & 5 & 1 & 81 & 6.75 & -1.28 \\
Surplus & 80.4 & 7 & 2 & 5 & 5.52 & -1.16 \\
Tubby & 84.3 & 7 & 2 & 27 & 5.25 & -1.22 \\
Wide & 98.0 & 5 & 2 & 0 & 6.23 & -2.06 \\
& 90.2 & 4 & 1 & 125 & 6.99 & -1.25
\end{tabular}


APPENDIX (Continued)

Word Lists for Testing Cognitive Biases

\begin{tabular}{|c|c|c|c|c|c|c|}
\hline Word & $\begin{array}{l}\text { Percentage } \\
\text { Agreement }\end{array}$ & $\begin{array}{l}\text { Number } \\
\text { of Letters }\end{array}$ & $\begin{array}{c}\text { Number of } \\
\text { Syllables }\end{array}$ & $\begin{array}{c}\text { Mean } \\
\text { Frequency }\end{array}$ & $\begin{array}{c}\text { Mean } \\
\text { Familiarity }\end{array}$ & $\begin{array}{c}\text { Mean } \\
\text { Valence }\end{array}$ \\
\hline \multicolumn{7}{|c|}{ Thin Stimuli } \\
\hline Anorexic & 91.2 & 8 & 4 & 0 & 6.91 & -2.49 \\
\hline Bony & 96.1 & 4 & 2 & 7 & 6.74 & -1.33 \\
\hline Brittle & 86.3 & 7 & 2 & 3 & 5.20 & -1.47 \\
\hline Fragile & 86.1 & 7 & 2 & 10 & 6.22 & -1.14 \\
\hline Frail & 93.1 & 5 & 1 & 8 & 6.09 & -1.51 \\
\hline Gangly & 82.4 & 6 & 2 & 0 & 4.86 & -1.22 \\
\hline Lanky & 91.2 & 5 & 2 & 2 & 5.54 & -0.80 \\
\hline Lightweight & 91.2 & 11 & 2 & 3 & 6.18 & 0.19 \\
\hline Narrow & 90.2 & 6 & 2 & 63 & 5.55 & -0.15 \\
\hline Petite & 86.3 & 6 & 2 & 1 & 6.64 & 0.47 \\
\hline Scrawny & 95.1 & 7 & 2 & 4 & 6.84 & -1.56 \\
\hline Skeletal & 96.1 & 8 & 3 & 13 & 5.84 & -1.70 \\
\hline Skinny & 98.0 & 6 & 2 & 9 & 7.57 & -0.17 \\
\hline Slender & 94.1 & 7 & 2 & 19 & 6.55 & 0.90 \\
\hline Slim & 95.1 & 4 & 1 & 20 & 7.42 & 1.02 \\
\hline Stringy & 88.2 & 7 & 2 & 3 & 4.90 & -1.11 \\
\hline Teeny & 83.3 & 5 & 2 & 4 & 5.44 & -0.35 \\
\hline Thin & 98.0 & 4 & 1 & 92 & 7.73 & 0.73 \\
\hline Threadlike & 90.2 & 10 & 2 & 0 & 4.48 & -1.35 \\
\hline Twiggy & 94.1 & 6 & 2 & 0 & 4.97 & -1.09 \\
\hline Weightless & 89.2 & 10 & 2 & 0 & 5.30 & -0.57 \\
\hline Wiry & 82.2 & 4 & 3 & 8 & 5.32 & -0.66 \\
\hline \multicolumn{7}{|c|}{ Muscular Stimuli } \\
\hline Athletic & 86.3 & 8 & 3 & 18 & 7.58 & 2.25 \\
\hline Buff & 99.0 & 4 & 1 & 5 & 6.59 & 1.66 \\
\hline Chiseled & 92.2 & 8 & 1 & 2 & 6.21 & 1.92 \\
\hline Cut & 82.4 & 3 & 1 & 192 & 6.27 & 1.53 \\
\hline Defined & 90.2 & 7 & 2 & 39 & 6.88 & 1.94 \\
\hline Firm & 89.2 & 4 & 1 & 109 & 6.89 & 1.51 \\
\hline Hard & 95.0 & 4 & 1 & 202 & 6.92 & 1.21 \\
\hline Hardened & 93.1 & 8 & 2 & 0 & 5.70 & 0.93 \\
\hline Hulky & 91.2 & 5 & 2 & 0 & 5.10 & 0.63 \\
\hline Mighty & 91.2 & 6 & 2 & 29 & 6.02 & 1.51 \\
\hline Muscular & 100.0 & 8 & 3 & 18 & 7.55 & 2.03 \\
\hline Powerful & 94.1 & 8 & 3 & 63 & 7.42 & 2.08 \\
\hline Pumped & 82.4 & 6 & 1 & 3 & 6.16 & 1.17 \\
\hline Ripped & 93.1 & 6 & 1 & 6 & 6.92 & 1.77 \\
\hline Sculpted & 93.1 & 8 & 2 & 1 & 6.37 & 1.91 \\
\hline Solid & 88.2 & 5 & 1 & 77 & 7.06 & 1.33 \\
\hline Strong & 96.1 & 6 & 1 & 16 & 7.64 & 2.03 \\
\hline Toned & 93.1 & 5 & 2 & 0 & 7.07 & 2.17 \\
\hline Tough & 81.4 & 5 & 1 & 36 & 7.31 & 1.28 \\
\hline
\end{tabular}

(Manuscript received September 9, 2005;

revision accepted for publication January 14, 2006.) 